\title{
Alterações da mucosa intestinal em ratos: estudo morfométrico em três diferentes tratamentos após indução experimental de sepse abdominal aguda ${ }^{1}$
}

\author{
Ricardo Tramonte², Roberta O. M. Carvalho ${ }^{3}$, Débora Cadore de Farias ${ }^{4}$, João Daniel May Serafim, \\ Daniel Knabben Ortellado ${ }^{6}$, Armando José d'Acampora ${ }^{7}$
}

\begin{abstract}
Tramonte R, Carvalho ROM, Farias DC, Serafim JDM, Ortellado, DK, d'Acampora AJ. Alterações da mucosa intestinal em ratos: estudo morfométrico em três diferentes tratamentos após indução experimental de sepse abdominal aguda. Acta Cir Bras [serial online] 2004 Mar-Abr;19(2). Disponível em URL: http://www.scielo.br/acb.

RESUMO - Objetivo: Verificar as possíveis alterações morfológicas da parede intestinal provocadas pela contaminação de uma monocultura bacteriana na cavidade abdominal de ratos, após tratamento por drenagem, lavagem e a combinação destes dois processos. Métodos: Foram utilizados 50 ratos fêmeas da linhagem Wistar, foram distribuídos em 5 subgrupos: grupo Controle (C) - recebeu um inóculo padrão com 1,2.10 de Pseudomonas aeruginosa, intraperitonial, sem nenhum tipo de tratamento; grupo Dreno (D) - inóculo padrão e realizada a drenagem da cavidade abdominal; grupo Lavado (L) - inóculo e realizada a lavagem da cavidade abdominal com solução salina; grupo L+D - inóculo e submetido aos dois tipos de tratamentos; grupo Normal $(\mathrm{N})$ sem nenhum tipo de inoculação ou tratamento. Realizou-se a análise morfométrica das lâminas coradas por H.E da mucosa intestinal e hemocultura. Resultados: Não houve diferenças estatisticamente significantes na espessura da mucosa intestinal entre os 5 subgrupos de ratos analisados no período de 24 horas após a injeção do inóculo. 37 animais que receberam o inóculo evoluíram para o óbtito entre 5,83 e 28 horas, com 2 animais do grupo L sobrevivendo por um período de 28 horas. Conclusão: A sepse aguda não causou alterações morfológicas mensuráveis através desta metodologia na parede intestinal.
\end{abstract}

DESCRITORES - Mucosa. Intestino. Ratos. Morfometria.

\section{Introdução}

A contaminação da cavidade peritoneal é considerada uma urgência médica, sua conseqüência mais temida é a sepse. Apesar do avanço científico, técnica cirúrgica minuciosa e terapia antimicrobiana adequada, a taxa de mortalidade da sepse de origem abdominal grave ainda continua em torno de 40 a $50 \%^{1,2,3,4,5}$ sendo semelhante àquela de quatro décadas atrás.

O modelo experimental de sepse é um método de estudo no qual é possível avaliar e controlar o fenômeno séptico como um processo dinâmico, desde a sua instalação até o desenvolvimento da falência terminal dos órgãos e sistemas ${ }^{6}$. A morte ocorre em virtude da disfunção de múltiplos órgãos e sistemas, secundária à manutenção da sepse intraperitoneal com focos residuais de infecção, ou em decorrência da translocação bacteriana e da liberação de mediadores inflamatórios. ${ }^{7,8,9}$

Acredita-se, que o intestino delgado e o colo são muito importantes na manutenção do hipermetabolismo da sepse, na síndrome da resposta inflamatória sistêmica e na disfunção de múltiplos órgãos e sistemas ${ }^{3,8,9}$, além de serem identificados como um dos alvos primários de lesão na sepse. ${ }^{10,11}$
Na cavidade abdominal dos mamíferos o peritônio tem funções importantes e responde à agressão séptica com ações envolvendo a membrana peritoneal, as alças intestinais e os compartimentos líquidos do organismo que produzem então respostas secundárias endócrinas, cardíacas, respiratórias, renais e metabólicas. O objetivo de tais respostas é neutralizar, destruir ou limitar a ação dos agentes agressores e fazer reparo das lesões por estes causadas. ${ }^{12} \mathrm{O}$ tratamento convencional para esta condição inclui administração de fluidos e antibióticos intravenosos e remoção da fonte de contaminação da cavidade peritonial. ${ }^{13}$ Neste tipo

1. Trabalho do Núcleo de Pesquisa da Técnica Operatória e Cirurgia Experimental da Universidade Federal de Santa Catarina (TOCE-UFSC).

2. Professor Adjunto, Doutor em Histologia do Núcleo de Pesquisa da TOCE-UFSC.

3. Médica Residente em Radiologia do Hospital Universitário da UFSC.

4. Aluna da Graduação em Medicina da UFSC.

5. Médico Residente em Cirurgia do Hospital Regional de São José, Santa Catarina.

6. Médico Residente em Cirurgia Geral do HU-UFSC.

7. Professor Adjunto, Doutor em Técnica Operatória e Cirurgia Experimental pela Universidade do Estado de São Paulo - Escola Paulista de Medicina (UNIFESP-EPM). Líder do Grupo de Pesquisa TOCE-UFSC. 
de tratamento geralmente utiliza-se a drenagem da cavidade peritoneal, com emprego de dreno intraperitonial para remoção da fonte de contaminação da cavidade.

Parte significativa da literatura e dos experimentos tem se dedicado ao uso tópico de soluções contendo antibióticos, para lavagem peritoneal após a inoculação intraperitoneal de bactérias ou de um pool de bactérias. ${ }^{14,15,16,17}$

Dentre os diversos tratamentos propostos para a contaminação peritoneal, dois são utilizados com maior freqüência: a drenagem e o lavado peritoneal, embora não haja provas científicas definitivas para sua utilização. . $^{18,19,20,21}$ Não há, ainda, parâmetros fixos que determinem a indicação sistematizada da drenagem e lavado abdominais, após a instalação deste tipo de contaminação.

Sob diversas condições nutricionais e patológicas, o intestino pode sofrer atrofia, comprometendo suas funções essenciais. A atrofia intestinal é manifestada por diminuição do peso da mucosa, do conteúdo de DNA e proteína da mucosa e por alteração na sua estrutura, através da visualização da mucosa intestinal macroscópicamente.

A luz do trato gastrointestinal normalmente contém numerosas espécies de bactérias, aumentando do proximal para o distal em espécies e quantidade ${ }^{6}$, e uma alta concentração de endotoxinas. Cabe à mucosa intestinal a função de exercer localmente uma defesa contra a absorção e disseminação desses agentes patógenos. ${ }^{22,23,24,25,26}$ Os microorganismos intracelulares facultativos (Salmonella spp e Listeria monocytogenes) e as bactérias Gram negativas podem atravessar a parede intestinal de forma razoavelmente fácil. ${ }^{6}$

A integridade física da mucosa provavelmente representa a principal linha de defesa dessa barreira intestinal ${ }^{26,27,28,29,30}$, sendo auxiliada pelos componentes do sistema imune celular (enterócitos, macrófagos e linfócitos T) e humoral (IgG, $\operatorname{IgM}$ e IgA secretória).

A manutenção da integridade celular do epitélio intestinal evita a migração transepitelial de partículas da luz intestinal, enquanto a preservação das junções intercelulares previne o movimento dessas partículas através dos canais paracelulares. ${ }^{28,29,31,32}$
Um aumento na absorção de macromoléculas, bactérias e toxinas bacterianas tem sido demonstrado em situações onde a mucosa intestinal está danificada por inflamação, infecção ou neoplasia. ${ }^{29} \mathrm{O}$ significado dessa afirmação ainda é difícil de ser determinado, mas os trabalhos mais recentes sugerem que a translocação de microorganismos e toxinas ativa uma reação inflamatória em cadeia que promove a falência orgânica. 22,23,24,26,30,31

A atrofia da mucosa do trato gastrointestinal (principalmente intestino delgado) na sepse é amplamente discutida na literatura. ${ }^{1,4,6,7,22,26,29,30,33,34,35}$ Entretanto, todos os trabalhos consultados utilizam métodos de indução de sepse que causam alterações lentas no organismo, tornando o tempo de sobrevida mais prolongado.

Para avaliar atrofia do intestino delgado, a maioria dos trabalhos encontrados na literatura utiliza parâmetros morfológicos através de análise patológica. Esses parâmetros incluem arquitetura da parede do trato gastrointestinal, evidências de congestão ou hemorragia, inflamação de mucosa e submucosa e necrose. . $^{36,37,38,39}$ Entretanto, todos esses parâmetros são subjetivos e dependem da observação do examinador, portanto qualitativos. ${ }^{40}$

$\mathrm{Na}$ literatura analisada, são raros os trabalhos que utilizam procedimentos histomorfométricos para avaliar os efeitos sobre a parede intestinal provocados por sepse, além disto, não existe nenhum trabalho que realiza a indução de sepse com Pseudomonas aeruginosa, ou seja, com uma monoculatura bacteriana e com tempo de sobrevida curto (em horas) a fim de verificar quais as alterações iniciais provocadas pela indução da sepse na mucosa intestinal após os tratamentos de lavagem e/ou dreno que são amplamente utilizados na prática médica após o estabelecimento de um processo séptico na cavidade abdominal.

Desta forma, propôs-se a avaliar morfométricamente a camada mucosa do intestino delgado de ratos após sepse experimental de origem abdominal empregandose técnicas que permitem quantificar as possíveis alterações morfológicas da mucosa intestinal em microscopia óptica ,comparando-se os 3 tipos de tratamento empregados após a indução de uma sepse provocada por um único tipo de bactéria.

\section{Métodos}

Este trabalho passou pela aprovação da Comissão de Ética em Uso de Animais da Universidade Federal de Santa Catarina (UFSC).

Para o presente trabalho foram utilizados 50 ratos fêmeas da linhagem Wistar, todos do sexo feminino, com idade média de 120 dias e peso entre 150 e $250 \mathrm{~g}$, provenientes do Biotério Central da UFSC.

Os animais receberam alimentação própria, com acesso livre a dieta e água durante todo o experimento, sendo mantidos sob luz natural, em gaiolas apropriadas e condições ambientais de ruído, temperatura e umidade, padronizadas. Os animais foram distribuídos em cinco subgrupos de dez ratos cada um, conforme a descrição a seguir:

1) Grupo controle - C: no qual injetou-se (1 ml de inóculo bacteriano para cada 100g de peso do animal) um inóculo padrão intraperitonealmente de Pseudomonas aeruginosa, por via transparietal em 10 (dez) ratos . Este inóculo padrão estava em solução aquosa de Cloreto de Sódio a $0,9 \%$, na quantidade de $1,2.10^{9}$ bactérias por mililitro de suspensão. Esses animais foram submetidos à avaliação clínica constante e não receberam nenhum tipo de tratamento.

2) Grupo dreno - D: injetou-se o mesmo inóculo padrão intraperitonealmente, por via transparietal em dez ratos. Esses animais foram submetidos à avaliação clínica constante e após seis horas da inoculação, os animais foram anestesiados e realizada uma antissepsia da parede abdominal, laparotomia e drenagem da cavidade abdominal através de um dreno laminar. Após a operação foi realizada observação clínica do animal até o momento do óbito.

3) Grupo lavado - L: injetou-se o mesmo inóculo padrão intraperitonealmente, por via transparietal em dez ratos. Esses animais foram submetidos à avaliação clínica constante e após seis horas da inoculação, os animais foram anestesiados e realizada antissepsia da parede abdominal, laparotomia e lavagem da cavidade abdominal com $20 \mathrm{ml}$ de solução aquosa de cloreto de sódio na concentração de $0,9 \%$. Após a operação foi realizada observação clínica do animal até o momento do óbito.

4) Grupo lavado + dreno - LD: injetou-se o mesmo inóculo padrão intraperitoneal- 
mente, por via transparietal em dez ratos. Esses animais foram submetidos à avaliação clínica constante e após seis horas da inoculação, os animais foram anestesiados e realizada antissepsia da parede abdominal, laparotomia, lavagem da cavidade abdominal com $20 \mathrm{ml}$ de solução aquosa de cloreto de sódio na concentração de $0,9 \%$ e drenagem da cavidade através de um dreno laminar. Após a operação foi realizada observação clínica do animal até o momento do óbito.

5) Grupo normal - N: Dez animais hígidos, os quais não receberam a injeção intraperitoneal do inóculo padrão, foram anestesiados e induzidos à eutanásia para obtenção de amostras de jejuno para avaliação morfométrica de parede intestinal normal.

Para a anestesia foi utilizada uma solução de Ketamina (5 ml) e Xilasina a 2\% (1 ml) sendo injetado $0,5 \mathrm{ml}$ da solução, pela via intramuscular, na face interna da pata traseira direita do animal. $\mathrm{O}$ animal foi considerado anestesiado, quando havia perdido o reflexo córneo-palpebral e não exibia qualquer reação motora pela preensão do coxim adiposo de sua pata dianteira. Realizou-se a síntese da parede abdominal por planos. Para as camadas peritoneal e muscular, foi utilizado fio de polipropileno 5-0, em chuleio contínuo interrompido a cada quatro pontos. A pele foi suturada com fio monofilamentar de Nylon ${ }^{\circledR}$ 5-0 com pontos simples.

Nos animais em que se usou o dreno abdominal, foram utilizados dispositivos tipo "colar cervical", conforme descrito por Ely e col. ${ }^{41}$ com o objetivo de manter a imobilidade da cabeça do animal e, portanto, evitar que o mesmo retirasse o dreno. Após o óbito, os animais foram submetidos a incisão tóraco-abdominal, para a realização do inventário das cavidades.

Foram realizadas hemoculturas de todos os grupos de animais experimentais, para isto, foi colhida uma amostra de $1 \mathrm{ml} \mathrm{de}$ sangue intracardíaco sob condições assépticas. Essa amostra foi preservada em meio específico para cultivo de bactérias aeróbicas (Pedi-BacT® - Lab. Organon Teknika).

Para avaliação histológica, foram retirados fragmentos de intestino delgado com $2 \mathrm{~cm}$ de comprimento, num ponto localizado a $5 \mathrm{~cm}$ distalmente ao ângulo de Treitz. As peças retiradas foram lavadas em solução salina e fixadas em solução de Bouin por um período de $24 \mathrm{hs}$. A seguir, as peças foram submetidas ao processo de inclusão em parafina, seguindo a técnica histológica de rotina adotada pelo serviço. Os tempos de desidratação e diafanização foram padronizados previamente, sendo os mesmos para todos os grupos experimentais de animais analisados.

Após a inclusão em parafina das peças de intestino delgado foram obtidos 10 cortes semi-seriados de $10 \mu \mathrm{m}$ de espessura segundo um mesmo plano de corte transversal ao intestino delgado de todos os animais . Os tempos de pescagem dos cortes foram padronizados para todos os grupos experimentais, a fim de se evitar alterações provocadas pelos procedimentos técnicos empregados na técnica histológica de rotina. As lâminas assim obtidas foram coradas pela Hematoxilina-Eosina e submetidas á análise morfométrica ${ }^{42}$. Com a régua ocular, previamente calibrada foram realizadas medidas da espessura total da parede do intestino delgado e da espessura da camada mucosa e submucosa em três (3) vilosidades intestinais. Apenas vilosidades seccionadas longitudinalmente da sua base até o seu ápice com uma única camada de células epiteliais foram consideradas para avaliação das espessuras do intestino delgado.

A medida da espessura total da parede do intestino delgado foi realizada colocando o ponto zero da régua ocular na camada serosa abaixo da vilosidade medindo-se a espessura até a última camada de células epiteliais em micrômetros.

A medida da camada mucosa e submucosa foi realizada colocando-se o zero da régua ocular entre as células da camada muscular circular interna e as da submucosa, medindo-se até a última camada de células epiteliais no ápice da vilosidade. Foram realizadas medidas das 3 (três) melhores vilosidades visualizadas, sendo utilizado como resultado, o valor médio dessas medidas.

\section{Resultados}

O tamanho médio das medidas obtidas da mucosa e da parede intestinal distribuídas entre os diversos grupos pode ser avaliada na Tabela 1.

TABELA 1 - Média em micrômetros, do tamanho da mucosa + submucosa de 3 vilosidades da parede intestinal de 10 ratos, distribuídos entre os diferentes grupos experimentais

\begin{tabular}{ccc}
\hline Grupos & Mucosa + Submucosa $(\mu \mathrm{m})$ & Parede intestinal $(\mu \mathrm{m})$ \\
\hline C & 385,0 & 488,8 \\
D & 388,6 & 498,6 \\
LD & 398,9 & 502,2 \\
L & 348,9 & 471,1 \\
N & 396,0 & 481,0 \\
Total & 383,4 & 488,3 \\
\hline
\end{tabular}

Quando esses resultados são submetidos ao estudo estatístico de Análise de Variâncias, que compara médias de diferentes grupos, não se identifica diferença estatisticamente significante entre os grupos (P>0,05).

Quanto à avaliação do tempo de óbito dos animais experimentais, pôde-se observar que dos 40 animais utilizados, 37 evoluíram para o óbito em um período de tempo que variou de 5,83 horas até 28 horas. Nos grupos controle e lavado + dreno, todos os animais evoluíram para o óbito nas primeiras 24 horas. No grupo dreno, 9 animais evoluíram para o óbito em até 36 horas, havendo um sobrevivente após esse período. No grupo lavado houve dois sobreviventes e o tempo de óbito foi de até 28 horas.

A Tabela 2 mostra o resultado obtido nas hemoculturas dos diversos grupos experimentais, com a obtenção de sangue intracardíaco colhido em condições assépticas e plaqueado em meio para cultivo de bactérias anaeróbicas (Pedi-BacTÒ-Lab. Organon Teknika). O resultado da hemocultura indica que dos 40 animais analisados, em 36 deles (90\%) houve crescimento de Pseudomonas aeruginosa na hemocultura e em 21 (52,5\%) houve crescimento de Escherichia coli.

A Tabela 3 apresenta o tempo médio de sobrevida dos animais experimentais que obtiveram êxito letal em até 36 horas, distribuídos entre os diferentes grupos. 
TABELA 2 - Resultado da hemocultura do sangue intracardíaco nos animais experimentais

\begin{tabular}{lcccc}
\hline Bactérias & $\begin{array}{l}\text { Positividade em } \\
\end{array}$ & Percentual de & Negatividade em & Percentual de \\
\multicolumn{2}{c}{ número de ratos } & & número de ratos & negatividade (\%) \\
\hline $\begin{array}{l}\text { Pseudomonas } \\
\begin{array}{l}\text { aeruginosa } \\
\text { Escherichia coli }\end{array}\end{array}$ & 36 & 90 & 4 & 10 \\
\hline
\end{tabular}

TABELA 3 - Tempo médio de sobrevida dos animais que evoluíram para o óbito antes de 36 horas após a inoculação de Pseudomonas aeruginosa

\begin{tabular}{c|c|c}
\hline Grupo & Tempo médio (hs.) & Desvio padrão \\
Controle & 14,88 & 2,36 \\
Dreno & 15,26 & 6,41 \\
Lavado & 18,21 & 5,42 \\
\hline Lavado/Dreno & 14,31 & 5,84 \\
\hline Total & 15,51 & 5,19
\end{tabular}

Estatisticamente, não foi possível $(\mathrm{p}>0,05)$ demonstrar diferença entre o tempo médio de óbito dos animais nos diferentes grupos experimentais.

Quando comparados o tempo de óbito dos animais experimentais com a medida da altura da camada mucosa e da parede intestinal, não foram encontradas diferenças estatisticamente significativas $(p>0,05)$ (Figura 1).

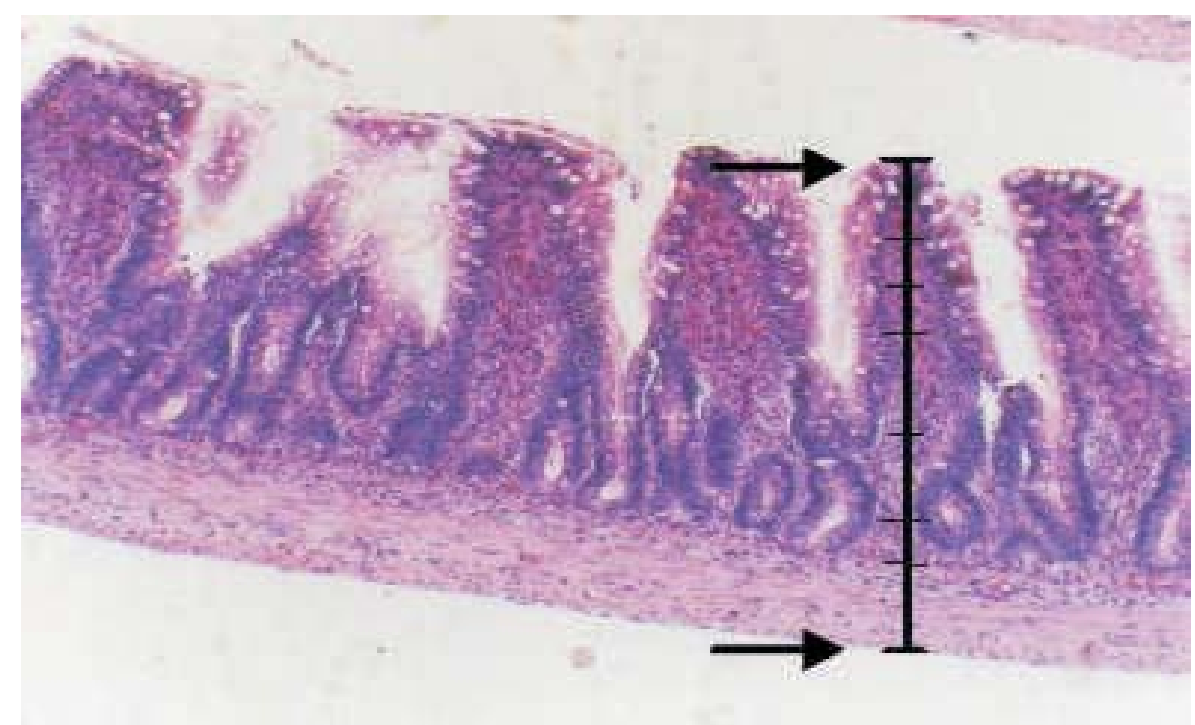

FIGURA 1 - Representação esquemática da mensuração de uma vilosidade da camada serosa até o epitélio (fotomicrografia com objetiva de 10X).

\section{Discussão}

A morfometria, quando utilizada para avaliar a atrofia da mucosa do trato gastrointestinal, torna-se um método objetivo s resultados de hemocultura e cultura peritoneal foram submetidos ao teste estatístico de análise de correspondência, para variáveis qualitativas, que não mostrou significância estatística $(\mathrm{p}>0,05)$ entre os diferentes grupos estudados.

Quando comparada à medida da altura da camada mucosa e da lâmina própria com os achados da hemocultura e cultura peritoneal, não se evidenciou diferença estatisticamente significante $(\mathrm{p}>0,05)$. dem apresentar modificações em seu tamanho após um desafio séptico. ${ }^{43,44,45}$

Além da sepse, a análise morfométrica também é utilizada em modelos experimentais de isquemia do trato gastrointestinal ${ }^{5,43,45}$, nutrição parenteral ${ }^{33,42}$, e colite..$^{40,44,43}$

A maior parte dos trabalhos na literatura pesquisada indica que a sepse e o choque séptico ocasionam uma diminuição importante da resistência vascular sistêmica e uma má distribuição do fluxo sanguíneo no organismo. . $30,38,42,44,45,46$

Essa redistribuição do fluxo sanguíneo privilegiaria áreas mais nobres como o cérebro e os rins em detrimento de órgãos como o trato gastrointestinal, pâncreas e, em menor proporção, a musculatura esquelética. ${ }^{10,11,45,47,48}$

Esse regime de isquemia, associado ao estado de hipermetabolismo próprio da sepse levaria à atrofia da mucosa.

Yassim e col. ${ }^{43}$ utilizando um método de isquemia e reperfusão, compararam a análise morfológica com a análise morfométrica da parede do intestino delgado. Foram encontradas nítidas alterações de tamanho nas vilosidades da camada mucosa na ausência de alterações morfológicas na microscopia óptica, concluindo que a morfometria tem uma sensibilidade maior que a análise morfológica no intestino delgado.

Neste trabalho não se verificou alterações estatisticamente significativas do tamanho das vilosidades intestinais nos diversos grupos experimentais analisados, já que o método empregado no presente experimento não provoca uma isquemia e analisa os resultados em tempos diferentes daqueles utilizados pelos autores supracitados. Suspeita-se que essa maior resistência à lesão do jejuno, quando comparada ao íleo ou ao colo, seja decorrente de uma maior vascularização desse segmento, havendo maior proteção contra a lesão isquêmica.

Zabel e col. ${ }^{47}$ demonstraram que existe um gradiente entre a $\mathrm{pO}_{2}$ da mucosa e a $\mathrm{pO}_{2}$ da serosa do trato gastrointestinal e que essa diferença se agrava em regimes de hipoperfusão.

Com base nesssas teorias, pode-se concluir que a sepse gera uma redistribuição do fluxo para fora da circulação esplâncnica e para longe da mucosa, tornando as vilosidades do intestino delgado o principal alvo da lesão isquêmica. 
A outra causa de lesão mucosa, provavelmente associada à hipoperfusão, é a pobre extração e utilização dos nutrientes (principalmente aminoácidos como a glutamina) pela mucosa do trato gastrointestinal, apesar das taxas normais de $\mathrm{O}_{2}{ }^{8,28,48}$ A glutamina é a principal fonte de energia para os enterócitos ${ }^{7,50}$ e na sepse ou endotoxemia a glutamina intestinal está reduzida, podendo causar alterações metabólicas locais e consequentemente atrofia mucosa. ${ }^{5,33,50,51,52,53}$

O método de morfometria utilizado neste experimento é semelhante ao método utilizado por Nascimento e col. ${ }^{42}$ e por Myers e col. ${ }^{37}$ utilizando para mensuração da altura das vilosidades uma régua adaptada à lente ocular do microscópio óptico.

Nakka e col. ${ }^{33}$, utilizando duas formas de nutrição parenteral total após sepse por E. coli em ratos, encontraram alterações no tamanho da mucosa apenas no íleo terminal, não encontrando alterações no jejuno, ou nos pontos médios do intestino delgado ou do colo. Estes resultados estão de acordo com os encontrados em nosso trabalho, já que analisamos a porção inicial do jejuno destes animais.

Esses trabalhos suportam a hipótese de que a mucosa do intestino delgado é mais responsiva a alterações tanto experimentais quanto clínicas, quando comparada com a mucosa do intestino grosso .

Os trabalhos mais recentes ${ }^{1,2,5,42,33,40}$ utilizam, para avaliar morfometricamente a altura da camada mucosa, imagens digitalizadas do microscópio óptico que são analisadas por um programa de computador específico.

Farges e col. ${ }^{36}$ utilizando lipopolissacarídeos de Escherichia coli para induzir endotoxemia em ratos encontraram uma diminuição da altura das vilosidades no íleo. Entretanto, a altura das vilosidades do jejuno não se alterou, assim como a profundidade das criptas, tanto no jejuno quanto no íleo.

No presente trabalho, foi avaliada apenas a altura da camada mucosa e da parede intestinal do jejuno. Assim como na literatura, no jejuno não houve alterações evidentes na parede intestinal que pudessem ser avaliadas à luz da microscopia óptica. A exata fisiopatologia da lesão na mucosa do intestino delgado ainda não está completamente elucidada.
Embora a atrofia da mucosa o tracto gastrointestinal (principalmente intestino delgado) na sepse seja amplamente discutida na literatura ${ }^{1,22,26,29,30,34,35,42}$, todos os trabalhos consultados utilizam métodos de indução de sepse que causam alterações lentas no organismo, tornando o tempo de sobrevida mais prolongado. No método utilizado de indução de sepse com Pseudomonas aeruginosa, o tempo de sobrevida médio entre todos os grupos foi de 15,5 horas, provavelmente não havendo tempo de evolução suficiente para causar uma atrofia de mucosa visualizável na microscopia óptica.

Com base no exposto acima, este trabalho nos permite concluir que a sepse aguda não causou alteração mensurável na parede intestinal ou na camada mucosa do intestino delgado empregando-se lavagem, dreno ou a associação dos dois processos no tratamento de ratas após o desafio séptico com Pseudomonas aeruginosa, provavelmente devido ao tempo extremamente curto de análise empregado neste modelo experimental.

\section{Conclusão}

A sepse aguda não causou alterações morfológicas mensuráveis na parede intestinal de ratos.

\section{Referências}

1. Doberneck RC, Mittelman J. Reappraisal of the problems of intra-abdominal abscess. Surg Gynecol \& Obstet 1982; 154:875-9.

2. Steinberg D. On leaving the peritoneal cavity open in acute generalized suppurative peritonitis. Am J Surg 1979; 137: 216-20.

3. Leiboff AR, Soroff HS. The treatment of generalized peritonitis by closed postoperative peritoneal lavage. Arch Surg 1987; 122: 1005-10.

4. Pitcher WD, Musher DM. Critical importance of early diagnosis and treatment of intra-abdominal infection. Arch Surg 1982; 117: 328-33.

5. Marik PE, Varon J. The hemodynamic derangements in sepsis: implications for treatment strategies. Chest 1998; 114(3): 854-60.

6. d'Acampora AJ. Avaliação histológica da sepse experimental em ratos Wistar [Tese Doutorado]. Universidade Federal de São Paulo - Escola Paulista de Medicina; 1996.

7. Hunt JL. Generalized peritonitis. Arch Surg 1982; 117: 209-11.

8. Buanes TA, Gunnar PA, Ulf J, Knut N. Perforated appendicitis with generalized peritonitis. Eur J Surg 1991; 157: 277-9.

9. Deitch EA. Multiple organ failure. Pathophysiology and potencial future therapy. Ann Surg 1992; 216: 117-34.
10. Bohnen JMA, Mustard RA. A critical look at scheduled relaparotomy for secondary bacterial peritonitis. Surg Gynecol \& Obstet 1993; 172: 25-9.

11. Duranteau J, Sitbon P, Teboul JL, Vicaut E, Anguel N, Richard C, et al. Effects of epinephrine, norepinephrine, or the combination of norepinephrine and dobutamine on gastric mucosa in septic shock. Crit Care Med 1999; 27(5):893-900.

12. Ahrenholz DH, Simmons RL. Peritonitis and other intra-abdominal infections. In: Simmons RL, Howard RJ. Surgical infections diseases. 2.ed. New York: Appleton Century Crofts; 1982. p.795-843.

13. Anderson ED, Mandelbaum DM, Ellison EC, Carey LC, Cooperman M. Open packing of the peritoneal cavity in generalized bacterial peritonitis. Am J Surg 1983;145:131-5.

14. Hunt JA, Rivlin ME, Clarebout HJ. Antibiotic peritoneal lavage in severe peritonitis. S A Medical Journal 1975; 49:233-8.

15. Hunt JL. Generalized peritonitis. Arch Surg 1982; 117:209-12

16. Lally, K.P.; Nichols, R.L. - Various intraperitoneal irrigation solutions in treating experimental fecal peritonitis. South Med J 1981; 74:789-91.

17. Lally KP, Trettin JC, Torma MJ. Adjunctive antibiotic lavage in experimental peritonitis. Surg Gynecol \& Obstet 1983; 156:605-8.

18. Ortellado DK, Carvalho ROM, Gerente MM, Bonin GS, Krause LS, d'Acampora AJ. Avaliação de 3 tipos de tratamento da peritonite experimental em ratos Wistar. Arq Cat Med 1999; 28(1/4):81-2

19. Dobrin PB, O'KEEFE, P, Tatarowicz W, Stachowski M, Freeark RJ. The value of continuous 72-hour peritoneal lavage for peritonitis. Am J Surg 1989; 157(4):368-71.

20. Stephen M, Loewenthal MS. Continuing peritoneal lavage in high-risk perotonitis. Surgery 1979; 85(6): 603-6.

21. Gerente MM, Ortellado DK, Carvalho ROM, Bonin GS, Santana LK, d'Acampora AJ. Dreno, Lavado em peritonite experimental em ratos Wistar. Rev Col Bras Cir 1999; 26(Supl 1): S395.

22. Alexander JW, Boyce ST, Babcock GF. The process of microbial translocation. Ann Surg 1990; 212: 496-512.

23. Wells CL, Maddaus MA, Simmons RL. Proposed mechanisms for the translocation of intestinal bacteria. Rev Infect Dis 1988; 10: 958-79.

24. Steffen EK, Berg RD, Deitch EA. Comparison of translocation rates of various indigenous bacteria from the gastrointestinal tract to the mesenteric lymph node. J Infect Dis 1988; 157: 1032-8.

25. Wells CL, Maddaus MA, Reynolds CM, Jechorek RP, Simmons RL. Role of anaerobic flora in the translocation of aerobic and facultatively anaerobic intestinal bacteria. Infect Immun 1987; 55: 2689-94.

26. Deitch EA. The role of intestinal barrier failure and bacterial translocation in the development of systemic infection and multiple organ failure. Arch Surg 1990; 125: 403-4.

27. Kazantsev GB, Hecht DW, Rao R, Fedorak IJ et al. Plasmid labeling confirms bacterial 
translocation in pancreatitis. Am J Surg 1994; 167(1): 201-7.

28. Van Leewuwen PAM, Boermeester MA, Houdijk APJ et al. Clinical significance of translocation. Gut 1994; 35(Supl. 1): S28-34.

29. Rowlands BJ, Soong CV, Gardiner KR. The gastrointestinal tract as a barrier in sepsis. Br Med Bull 1999; 55(1): 196-211.

30. Gennari R, Alexander JW. Effects of hyperoxia on bacterial translocation and mortality during gut-derived sepsis. Arch Surg 1996; 131(1): 57-62.

31. McCauley RD, Heel KA, Christiansen KJ, Hall JC. The effect of minimum luminal nutrition on bacterial translocation and atrophy of the jejunum during parenteral nutrition. J Gastroenterol Hepatol 1996; 11(1): $65-70$

32. Lemaire, LCJM, Van Lanschot JJB, Stoutenbeek CP, Van Deventer SJH, Wells CL, Gouma DJ. Bacterial translocation in multiple organ failure: cause or epiphenomenon still unproven. Br J Surg 1997; 84(10): 1340-50.

33. Naka S, Saito H, Hashiguchi Y, Lin MT, Furakawa S, Inaba T et al. Alanylglutamineenriched total parenteral nutrition improves protein metabolism more than branched chain amino acid-enriched total parenteral nutrition in protracted peritonitis. J Trauma 1997; 42(2): 183-90.

34. Wells CL, Maddaus MA, Simmons RL. Proposed mechanisms for the translocation of intestinal bacteria. Rev Infect Dis 1988; 10: 958-79.

35. Gianotti L, Alexander JW, Fukushima R, Childress C. Translocation of Candida albicans is related to the blood flow of individual intestinal villi. Circ Shock 1993; 40:250-7.
36. Farges MC, Raul F, Cezard JP, Davot P, Meunier MT, Cynober L, et al. A pancreatic extract-enriched diet corrects ileal mucosa atrophy in endotoxemic aged rats. Dig Dis Sci 1998; 43(10): 2244-50.

37. Myers JA, Hollinger EF, Mall JW, Jakate SM, Doolas, A, Saclarides TJ. Mechanical, histologic, and biochemical effects of canine rectal formalin instillation. Dis Colon Rectum 1998; 41(2): 153-8.

38. Fink MP, Cohn SM, Lee P. Effect of lipopoplysaccharide on intestinal intramucosal hydrogen ion concentration in pigs: evidence of gut ischemia in a normodynamic model of septic shock. Crit Care Med 1989; 17: 641-6.

39. Sedman PC, MacFie J, Palmer MD, Mitchell CJ, Sagar PM. Preoperative total parentera nutrition is not associated with mucosal atrophy or bacterial translocation in humans. Br J Surg 1995; 82(12): 1663-7.

40. Puglisi RN, Whalen TV, Doolin EJ. Computer analyzed histology of ischemic injury to the gut. J. Pediatr Surg 1995; 30(6): 839-44.

41. Ely PB, d'Acampora AJ, Miltersteiner AR, Hoff FC. Dispositivo do tipo colar cervical para proteção de ferida operatória abdominal em ratos. Acta Cir Bras 1997; 12( Supl 2): S15-6.

42. Nascimento AJE, Silva LRF, Oliveira AF, Silva MHG. Enhanced mucosal reepithelization induced by short chain fatty acids in experimental colitis. Braz $\mathrm{J}$ Med Biol Res 1999; 32(8): 961-6.

43. Yassin MMI, Barros AAB, Parks TG, McCaigue, MD, Leggett P, Halliday MI, et al. Lower limb ischaemia-reperfusion injury alters gastrointestinal structure and function. Br J Surg 1997; 84(10): 1425-9.
44. Vincent P, Colombel JF, Lescut D. Bacterial translocation in pacients with colorectal cancer. J Infect Dis 1988; 158: 1395-6.

45. Winslow C, Dorinski PM. Regional blood flow distribution in endotoxin-treated dogs: modification by ibuprofen. J Crit Care 1994; 9: $159-68$.

46. Marik PE, Varon J. The hemodynamic derangements in sepsis: Implications for treatment strategies. Chest 1998; 114(3): 854-60

47. Zabel DD, Hopf HW, Hunt TK. Transmural gut oxigen gradients in shocked rats resuscitated with heparan. Arch Surg 1995;130: 59-63

48. Lam C, Tyml K, Martin C, Sibbald W. Microvascular perfusion is impaired in a rat model of normotensive sepsis. J Clin Invest 1994; 94(5): 2077-83.

49. Alpers DH. Is glutamine a unique fuel for small intestinal cells? Curr Opin Gastroenterol 2000; 16(2): 155.

50. Sodeyama M, Gardiner KR, Regan MC, Kirk SJ, Efron G, Barbul A. Scientific papers: Sepsis impairs gut amino acid absorption. Am J Surg 1993; 165(1): 150-4.

51. Van Leeuwen PAM, Boermeester MA, Houdijk APJ. Clinical significance of translocation. Gut 1994; 35(Supl. 1): S28-34.

52. Mishima S, Xu D, Lu Q, Deitch EA. The relationships among nitric oxide production, bacterial translocation, and intestinal injury after endotoxin challenge in vivo. J Trauma 1998; 44(1): 175-82.

53. Katayama M, Xu D, Specian R, Deitch EA. Role of bacterial adherence and the mucus barrier on bacterial translocation: Effects of protein malnutrition and endotoxin in rats. Ann Surg 1997; 225(3): 317-26.

\begin{abstract}
Tramonte R, Carvalho ROM, Farias DC, Serafim JDM, Ortellado, DK, d'Acampora AJ. Alterations of intestinal mucosa in rats: morphometric study in three kinds of treatment after experimental acute abdominal sepsis induction. Acta Cir Bras [serial online] 2004 Mar-Apr;19(2). Available from URL: http://www.scielo.br/acb.

ABSTRACT - Purpose: To verify which are the possible morphological alterations caused by the contamination of a bacterial monoculture in the abdominal cavity of rats, after treatment by draining, washing and the combination of those two processes. Methods: Fifty adult female rats were distributed in five groups: 1. Control: intraperitoneal injection of Pseudomonas aeruginosa. 2. Drainage: intraperitoneal injection of P.aeruginosa and drainage of the abdominal cavity, after 6 hours. 3 . Washed intraperitoneal injection of P.aeruginosa and washing of the abdominal cavity, after 6 hours. 4. Washed + drainage: intraperitoneal injection of P.aeruginosa plus drainage and washing of the cavity, after 6 hours 5. Normal: evaluation of the normal intestinal wall. After death, blood culture and peritoneal culture were performed. Fragments of jejunum were removed and processed histologically for morphometric measure. Results: There were not statistically significant differences on the intestinal mucosa's thickness between the 5 groups analyzed in the period of 24 hours. From the 40 animals which received the inoculum, 37 evoluted to death in between 5.83 and 28 hours, with 2 animals from group L surviving for a period of 28 hours. Conclusion: The acute sepsis did not cause measurable morphological alterations through this methodology in the intestinal wall of these animals.
\end{abstract}

KEY WORDS - Mucosa. Morphometry. Rats. Intestin.

Correspondência:

Armando José d'Acampora

Condomínio San Diego, casa 9

Parque São Jorge - Itacorubi

88034-420 Florianópolis - Sc

acampora@ccs.ufsc.br
Conflito de interesse: nenhum Fonte de financiamento: nenhuma

Data do recebimento: 05/12/2003

Data da revisão: 09/01/2004

Data da aprovação: 25/01/2004 